\title{
Nicotine responses in hypersensitive and knockout $\alpha 4$ mice account for tolerance to both hypothermia and locomotor suppression in wild-type mice
}

\author{
Andrew R. Tapper ${ }^{1,3}$, Sheri L. McKinney ${ }^{1}$, Michael J. Marks ${ }^{2}$, and Henry A. \\ Lester $^{1}$ \\ ${ }_{1}^{1}$ Division of Biology, California Institute of Technology, Pasadena, CA 91125 \\ ${ }^{2}$ Institute for Behavioral Genetics, University of Colorado, Boulder, CO 80309 \\ ${ }^{3}$ Brudnick Neuropsychiatric Research Institute, University of Massachusetts Medical School, \\ Worcester, MA 01604
}

Brief Title: Nicotine tolerance predicted from mutants

*Corresponding author: Henry A. Lester, lester@ caltech.edu

156-29 Caltech, Pasadena CA 91125

phone 626-395-4946; fax 626-564-8709

Acknowledgements:

Funding from NIH NRSA (AT), DA-17279, DA19375, California TRDRP, and Philip Morris USA / International is gratefully acknowledged.

Key words: nicotine, addiction, nicotinic receptors, hypothermia, locomotion 


\section{Abstract}

Nicotinic receptors containing the $\alpha 4$ subunit $\left(\alpha 4^{*} \mathrm{nAChRs}\right.$ ) have high sensitivity and are widely expressed in the CNS, yet their contributions to behavioral tolerance, a hallmark of nicotine dependence, are unclear. To evaluate the contribution of $\alpha 4^{*}$ - and non- $\alpha 4$ nAChRs in the development of tolerance to hypothermia and locomotor suppression, $\alpha 4$ knockout (KO), hypersensitive Leu9'Ala $\alpha 4$ knock-in, and wild-type (WT) mice received daily nicotine injections, and their behaviors were compared. Repeated selective activation of $\alpha 4^{*} \mathrm{nAChRs}$ in Leu9'Ala mice produced profound tolerance to hypothermia over 7 days, whereas no tolerance was observed in $\alpha 4 \mathrm{KO}$ animals. The summed time course and temperature response (after appropriate normalizations) from these two mutant mouse strains resembled the time course of WT tolerance. In addition, daily selective activation of $\alpha 4^{*} \mathrm{nAChRs}$ elicited locomotor activation in Leu9'Ala mice, but nicotine suppressed activity in $\alpha 4 \mathrm{KO}$ mice and this did not change with daily drug exposure. Again, appropriately combined responses from the two mutant strains resembled the biphasic nicotine-induced activity in WT animals. Thus, by analyzing nicotinic responses in two complementary mouse lines, one lacking $\alpha 4^{*} \mathrm{nAChRs,}$ the other expressing hypersensitive $\alpha 4^{*} \mathrm{nAChRs}$, one can accurately separate non- $\alpha 4$ $\mathrm{nAChR}$ responses from $\alpha 4 \mathrm{nAChR}$ responses, and one can also account for WT tolerance to both hypothermia and locomotor suppression. Our study suggests a new paradigm for bridging the gap between genetic manipulation of a single receptor and whole-animal behavioral studies, and shows that activation of $\alpha 4^{*}$ $\mathrm{nAChRs}$ is both necessary and sufficient for the expression of tolerance. 


\section{Introduction}

Neuronal $n A C h R s$ are cation-selective ligand-gated ion-channels that are activated by the endogenous ligand, acetylcholine, as well as the naturally occurring alkaloid found in tobacco, nicotine. At present, 12 neuronal nicotinic acetylcholine receptor subunits have been identified ( $\alpha 2-10$ and $\beta 2-4)(12)$. The majority of subunits form functional heteromeric pentamers while a subset may form homomeric receptors. Thus, a myriad of $\mathrm{nAChR}$ subtypes may exist. Identification of $\mathrm{nAChR}$ subtypes specifically involved in dependence-related behaviors will give insights into the mechanism of nicotine dependence and will help to identify specific neural circuits that participate in addiction(17).

Previously, we have engineered and characterized a mouse line expressing a single point mutation in the M2 domain of the $\alpha 4 \mathrm{nAChR}$ subunit(3, 7, 16). This mutation, Leu9'Ala, renders $\alpha 4^{*} \mathrm{nAChRs}$ hypersensitive to nicotine by $\sim 50$-fold compared with wild-type (WT) mice. In the absence of specific agonists, this "knock-in" Leu9'Ala mouse line allows for the selective activation of $\alpha 4^{*}$ receptors with small doses of nicotine that do not activate other nAChR subtypes. Leu9'Ala mice exhibit dependence-related behaviors including tolerance and sensitization when challenged with daily injections of nicotine at doses that have little affect in wild-type animals. However, locomotor and hypothermia tolerance profiles in Leu9'Ala mice differ from those of wild-type mice tested at 50-fold higher nicotine doses, indicating that $\alpha 4^{*} \mathrm{nAChR}$-mediated responses in WT mice are likely confounded by responses due to activation of other non- $\alpha 4^{*} \mathrm{nAChR}$ subtypes. Indeed, nicotine doses required to elicit physiological responses in wild-type mice, and those doses that occur in smokers, activate multiple receptor subtypes $(6,19)$.

Mouse strains have also been developed that lack $\alpha 4$ nAChR receptors $(9$, 15). In this report, we utilize these two, complementary mouse models to evaluate the role of $\alpha 4^{*} \mathrm{nAChRs}$ in the response to nicotine. The Leu9'Ala line can be used to selectively activate $\alpha 4^{*}$ nAChRs with low doses of nicotine. The $\alpha 4$-null or knockout line $(\alpha 4 \mathrm{KO})$ allows us to determine the response to nicotine that is mediated by non- $\alpha 4^{*}$ nAChRs. We ask whether experimental data can be subjected to simple algorithms that account for the WT nicotine effects based on responses from these two mutant strains. A comparison of nicotine-mediated effects in these two lines does implicate $\alpha 4^{*}$ nAChRs in a hallmark of dependence: tolerance.

\section{Methods}

\section{Mice}

All experiments were conducted in accordance with the guidelines for care and use of animals provided by the National Institutes of Health, as well as with an approved animal protocol from the California Institute of Technology animal care and use committee. Animals were kept on a standard $12 \mathrm{hr}$ light/dark cycle and 
given food and water ad libitum. To minimize variability in responses due to genetic background differences, mice from both Leu9'Ala and $\alpha 4 \mathrm{KO}$ lines were back-crossed at least eight generations to the C57BL/6J strain with the exception of animals used for figure $3 A$ and $B$ which were back-crossed at least 3 generations (8).

\section{Telemetry Probes}

Vital View PDT-4000 temperature and activity telemetric probes were used (Respironics, Inc.). For implantation, mice were anesthetized with halothane, and a $1 \mathrm{~cm}$ incision was made at the back of the neck. Probes were inserted subcutaneously into the back. The incision was sealed with surgical glue and the mice were allowed to recover for $48 \mathrm{hr}$. Temperature and activity data were acquired at $30 \mathrm{sec}$ intervals using Vital View software and analyzed in Origin.

\section{Nicotine Administration}

Nicotine base was used in all behavioral experiments and administered through i.p. injection with $1 \mathrm{ml}$ syringes. Nicotine, mecamylamine, and $\mathrm{SCH} 29930$ were obtained from Sigma. Animals were injected daily with saline for at least three days prior to the start of each temperature and activity experiment, and average temperature changes for saline injections were $<0.2 \stackrel{\circ}{\circ}$. Pre-injection with $\mathrm{SCH} 29930$ did not produce significant temperature changes compared to saline. All activity and body temperature measurements were recorded in the home cage.

\section{Calculations}

\section{Predicted hypothermia tolerance profiles}

We assume that, in WT mice, there are at least two components of nicotine-induced hypothermia, and that these are mediated by at least two $\mathrm{nAChR}$ subtypes whose pathways are parallel and additive. We therefore write, $\Delta T_{W T}=\Delta T_{A}+\Delta T_{N}$, where $\Delta T_{W T}$ is the total change in body temperature for WT, $\Delta T_{A}$ is the change in body temperature due to activation of $\alpha 4^{*}$ nAChRs, and $\Delta T_{N}$ is the change in body temperature due to activation of non- $\alpha 4^{\star}$ nAChRs.

For Leu9'Ala mice injected with $0.015 \mathrm{mg} / \mathrm{kg}$ nicotine, $\Delta T_{\text {Leu''Ala }}=\Delta T_{A}$; whereas, for $\alpha 4 \mathrm{KO}$ mice injected with $2 \mathrm{mg} / \mathrm{kg}$ nicotine, $\Delta T_{a 4 K O}=\Delta T_{N}$. Thus, we predict that $\Delta T_{W T}=\Delta T_{\text {Leu''Ala }}+\Delta T_{a 4 K O}$ for each daily exposure to nicotine.

To measure tolerance to nicotine-induced hypothermia, we injected Leu9'Ala, $\alpha 4 \mathrm{KO}$, and WT mice with $0.015 \mathrm{mg} / \mathrm{kg}, 2 \mathrm{mg} / \mathrm{kg}$ nicotine, and $2 \mathrm{mg} / \mathrm{kg}$ nicotine, (i.p.), respectively, once daily over the course of seven days. WT mice received $2 \mathrm{mg} / \mathrm{kg}$ nicotine for comparison because this dose would be expected to maximally activate high-sensitivity $\alpha 4^{*} \mathrm{nAChRs}$ while also activating lowersensitivity, non- $\alpha 4^{*}$ nAChRs, presumably activated by the same dose in $\alpha 4 \mathrm{KO}$ mice. Doses $>2 \mathrm{mg} / \mathrm{kg}$ induce seizures in appreciable numbers of mice and, therefore, were not tested. This strategy could be confounded by compensatory 
or developmental changes in expression of other nAChR subtypes in Leu9'Ala or a4 KO mice. However, to date, radioligand binding and in situ hybridization analyses have revealed no such changes $(3,15,16)$.

We measured the maximal change in temperature (usually negative) within 40 min after a nicotine injection on day $n$; usually this extremum occurred at $\sim 25 \mathrm{~min}$. We averaged these changes for all mice of each genotype to obtain $\Delta T(n)_{\mathrm{N}}, \Delta T(n)_{A}, \Delta T(n)_{W T}$ on each day $n$. We then define

$$
\begin{aligned}
& \Delta t(n)_{N}=\Delta T(n)_{N} /\left(\Delta T(1)_{A}+\Delta T(1)_{N}\right), \\
& \Delta t(n)_{A}=\Delta T(n)_{A} /\left(\Delta T(1)_{A}+\Delta T(1)_{N}\right), \\
& \Delta t(n)_{W T}=\Delta T(n)_{W T} / \Delta T(1)_{W T} . \\
& \text { In most cases, }-1<\Delta t(n)_{N}, \Delta t(n)_{A}, \Delta t(n)_{W T}<0 .
\end{aligned}
$$

Thus, we predict WT activity after a nicotine injection on day $n$ :

$$
\Delta t(n)_{W T}=\Delta t(n)_{N}+\Delta t(n)_{A}
$$

\section{Predicted locomotor profiles}

We assume there are at least two nicotine-induced components that affect locomotor activity in WT mice, an $\alpha 4^{*} \mathrm{nAChR}$ and non- $\alpha 4^{*} \mathrm{nAChR}$ component. We write, $L=B_{W T} W=B_{W T} \bullet(A N)$, where $L$ is total locomotor activity after nicotine exposure, and $B$ is the average baseline activity over 30 minutes immediately following a saline injection. $A, N$, and $W$ are positive dimensionless parameters. A describes the effect of $\alpha 4^{\star} \mathrm{nAChR}$ activation on activity and equals unity for the KO strain. $N$ describes the non- $\alpha 4^{*} n A C h R$ effect on activity and equals unity for nicotine doses too low to activate non- $\alpha 4$ receptors. The parameter $W$ is defined similarly for WT mice. Because activity is affected in opposite directions for $\alpha 4 \mathrm{KO}$ and Leu9'Ala strains but cannot have a negative value, multiplication is more appropriate than simple addition for combining the two processes; thus $W=A N$. For Leu9'Ala mice injected with $0.015 \mathrm{mg} / \mathrm{kg}$ nicotine $L_{A}=B_{A} A$. Then $A=L_{A} / B_{A}$. For $\alpha 4 \mathrm{KO}$ mice injected with $2 \mathrm{mg} / \mathrm{kg}$ nicotine, $L_{N}=B_{N} N$. Then, $N=T_{N} / B_{N}$.

To measure locomotor effects of nicotine, we injected Leu9'Ala, $\alpha 4 \mathrm{KO}$, and WT mice with $0.015 \mathrm{mg} / \mathrm{kg}, 2 \mathrm{mg} / \mathrm{kg}$ nicotine, and $2 \mathrm{mg} / \mathrm{kg}$ nicotine, (i.p.), respectively, once daily over the course of six days. We averaged total activity during 30 min immediately after each nicotine injection for all mice of each genotype to obtain $L(n)_{A}, L(n)_{N}$, and $L(n)_{W T}$ on each day, $n$. Then:

$$
L_{N}(n)=B_{N} N(n)
$$




$$
L_{A}(n)=B_{A} A(n)
$$

Thus, one predicts WT activity after a nicotine injection on day $n$ :

$$
L_{W T}(n)=B_{W T} A(n) N(n)
$$

\section{Statistical tests}

Significance in all experiments was determined by one-way ANOVA followed by post-hoc analysis (Tukey test unless otherwise stated).

\section{Results}

\section{Hypothermia}

Acute nicotine injection elicits hypothermia in mice(13). Figure $1 \mathrm{~A}$ illustrates the dose-response relationships for nicotine-induced hypothermia in WT, Leu9'Ala, and $\alpha 4 \mathrm{KO}$ mice. Previously, we reported that Leu9'Ala exhibit a leftward-shifted dose response relationship compared to WT(16). We repeat this result here, using Leu9'Ala mice on a congenic, C57BL/6J background. The congenic Leu9'Ala mice are approximately 50-fold more sensitive than WT to the hypothermic effects of nicotine, similar to the previously studied Leu9'Ala mutant line on a mixed genetic background.

In $\alpha 4$ knockout mice, $0.5 \mathrm{mg} / \mathrm{kg}$ nicotine does not elicit hypothermia; and this is significantly different from the nicotine effect in WT animals $\left(1.09 \pm 0.07^{0} \mathrm{C}\right.$ in $\alpha 4$ KOs compared to $-2.08 \pm 0.390^{\circ} \mathrm{C}$ in WT, $p<0.001, F_{1,14}=97.4$, Fig. $1 \mathrm{~A}$ ). When challenged with higher doses of nicotine, 1 or $2 \mathrm{mg} / \mathrm{kg}, \alpha 4 \mathrm{KO}$ mice do exhibit hypothermia although at significantly less levels than WT mice challenged with the same dose. It is not possible to provide $E D_{50}$ values because two of the dose-effect relations do not saturate at high nicotine doses; instead, we present nicotine doses that induced a $2^{0} \mathrm{C}$ decrease: $0.009,0.4$, and $1.7 \mathrm{mg} / \mathrm{kg}$, for L9'A, $\mathrm{WT}$, and $\alpha 4$ respectively.

We previously reported that in WT and Leu9'Ala mice, the non-competitive nicotinic antagonist, mecamylamine, significantly blocked nicotine-induced hypothermia (16). We now report that mecamylamine also blocked nicotineinduced hypothermia in $\alpha 4 \mathrm{KO}$ mice. The body temperature of $\alpha 4 \mathrm{KO}$ mice challenged with $2 \mathrm{mg} / \mathrm{kg}$ nicotine $15 \mathrm{~min}$ after a saline injection decreased $2.74 \pm$ $0.31^{\circ} \mathrm{C}$ while body temperature dropped only $0.80 \pm 0.11^{\circ} \mathrm{C}$ in $\alpha 4 \mathrm{KO}$ mice pretreated with $2 \mathrm{mg} / \mathrm{kg}$ mecamylamine $\left(p<0.001, F_{1,9}=29.4\right.$, Fig. 1B). The peripheral nicotinic receptor antagonist, hexamethonium, did not significantly block nicotine induced hypothermia in either $\alpha 4 \mathrm{KO}$ or Leu9'ala mice $(1 \mathrm{mg} / \mathrm{kg}$, data not shown, NS, $n=6$ per genotype).

Direct and indirect dopamine agonists elicit hypothermia in rodents $(1,2)$, and previously, we found that Leu9'Ala mice express hypersensitive $\alpha 4^{*} n A C h R s$ in midbrain dopaminergic neurons, suggesting that nicotine-induced hypothermia may have a dopamine-dependent component(16). The D1 antagonist SCH29930 significantly attenuates nicotine induced hypothermia in Leu9'Ala 
animals (sal $+0.03 \mathrm{mg} / \mathrm{kg}$ nicotine $=-3.26 \pm 0.46^{\circ} \mathrm{C}$ compared to $-1.60 \pm 0.30^{\circ} \mathrm{C}$ in mice treated with $2 \mathrm{mg} / \mathrm{kg} \mathrm{SCH} 29930+0.03 \mathrm{mg} / \mathrm{kg}$ nicotine, $\mathrm{p}<0.01, \mathrm{~F}_{1,12}=$ 9.78, Fig. 1C). However, SCH29930 did not significantly block nicotine-induced hypothermia in $\alpha 4$ knockout mice $\left(-2.99 \pm 0.17\right.$ compared to $-3.05 \pm 0.28^{\circ} \mathrm{C}$, NS, Fig. 1D).

To compare tolerance profiles in Leu9'Ala, $\alpha 4 \mathrm{KO}$, and WT mice, we recorded hypothermia induced by single daily injections of nicotine. Figure $2 \mathrm{~A}$ illustrates representative body temperature recordings in $\alpha 4 \mathrm{KO}$ and Leu9'Ala homozygous mice immediately after nicotine injection $(2 \mathrm{mg} / \mathrm{kg}$ and $0.015 \mathrm{mg} / \mathrm{kg}$, i.p. respectively) on exposure day 1,4 , or 7 . Similar to our previous findings, selective activation of Leu9'Ala nAChRs with $0.015 \mathrm{mg} / \mathrm{kg}$ nicotine is sufficient for the development of tolerance. After 7 injections of nicotine over 7 days, nicotineinduced hypothermia is decreased by $78.8 \pm 13.3 \%$ (Fig. $2 \mathrm{~B}, \mathrm{p}<0.01, \mathrm{~F}_{1,12}=$ 11.8). To determine whether non- $\alpha 4^{*} n A C h R s$ are also necessary for a component of tolerance, we injected $\alpha 4 \mathrm{KO}$ animals with $2 \mathrm{mg} / \mathrm{kg}$ nicotine daily for seven days. The hypothermic response of $\alpha 4 \mathrm{KO}$ mice measured after seven days of treatment was not significantly different than the response following the first injection; thus, tolerance did not develop (day $1=-2.40 \pm 0.26^{\circ} \mathrm{C}$ compared to day $7=-2.28 \pm 0.23^{\circ} \mathrm{C}$, NS, Fig. $2 \mathrm{~A}$, and $2 \mathrm{~B}$ ). The right-hand axis of Figure $2 \mathrm{~B}$ gives the scale for the parameters defined in Eqs. 1 and 2).

Figure $2 \mathrm{C}$ illustrates the tolerance profile of WT in response to daily injections of $2 \mathrm{mg} / \mathrm{kg}$ nicotine. WT mice developed significant tolerance by the seventh injection (Day 1: $-4.74 \pm 0.17^{0} \mathrm{C}$ compared to Day 7: $-2.11 \pm 0.21^{\circ} \mathrm{C}, \mathrm{p}$ $\left.<0.001, F_{1,8}=57.8\right)$. This level of tolerance differed from tolerance profiles in Leu9'Ala or $\alpha 4 \mathrm{KO}$ mice by themselves (WT \% attenuation between Days 1 and 7: $49 \pm 4.8 \%$ compared to $78 \pm 13.3 \%$ in Leu9'Ala and $-4.9 \pm 9.4 \%$ in $\alpha 4 \mathrm{KO}$ mice, $\bar{p}<0.01, F_{2,14}=14.2$ ). The right-hand axis of Figure $2 \bar{C}$ gives the scale for the parameter defined in Eq. 3.

Together, our data suggest that the nicotine-induced hypothermia in wildtype mice is determined by the combination of activating both $\alpha 4^{*}$ and non- $\alpha 4^{*}$ $\mathrm{nAChRs}$, but that $\alpha 4^{*} \mathrm{nAChRs}$ alone are primarily responsible for the magnitude of tolerance that develops with continued nicotine exposure. To test this hypothesis, given by Eq. 4,, we summed the tolerance profiles from Leu9'ala and $\alpha 4 \mathrm{KO}$ to predict the tolerance profile in wild-type animals (Eq. 4). Figure 2D illustrates the normalized predicted tolerance profile compared to the actual tolerance profile from wild-type mice. The WT response was nearly identical to the predicted profile generated from the summed profiles of the two lines (Fig. 2D).

\section{Locomotor activity}

Previously, we reported that selective activation of $\alpha 4^{*} \mathrm{nAChRs}$ with nicotine in Leu9'Ala mice activates locomotor activity after multiple drug exposures. This effect is blocked by mecamylamine and also by the D1 antagonist $\mathrm{SCH} 23390$ [2]. Figure 3 illustrates dose-response relationships between nicotine and changes in locomotor activity in WT (Fig. 3A) and Leu9'Ala mice (Fig. 3B). Selective 
activation of $\alpha 4^{*}$ nAChRs with 0.015 or 0.030 but not 0.01 or $0.0075 \mathrm{mg} / \mathrm{kg}$ nicotine in Leu9'Ala mice activates locomotion after multiple drug exposures. WT mice exhibit no significant changes in activity after exposures to low doses of nicotine that induce activity in Leu9'Ala mice (Fig. 3A, $0.015 \mathrm{mg} / \mathrm{kg}$ nicotine). However, with larger doses, nicotine does alter activity in a dose dependent manner.

To determine a dose of nicotine that elicits an effect on locomotor activity in $\alpha 4 \mathrm{KO}$ mice, we injected mice acutely with $0.5,1.0$ or $2.0 \mathrm{mg} / \mathrm{kg}$ nicotine. Compared to saline and consistent with previous reports $(9,15)$, neither 0.5 nor $1.0 \mathrm{mg} / \mathrm{kg}$ nicotine had a significant effect on locomotor activity; whereas 2.0 $\mathrm{mg} / \mathrm{kg}$ significantly suppressed activity similar to WT mice $\left(p<0.01 . F_{1,14}=15.9\right.$ Fig. 3 C). In addition, this suppression of nicotine was significantly blocked by mecamylamine, indicating that the effect was mediated via $\mathrm{nAChR}$ activation (Fig. 3D).

Figure $4 \mathrm{~A}$ and $\mathrm{B}$ depict the pattern of locomotor activity for $30 \mathrm{~min}$ immediately after saline injection, or after one or six single daily injections of nicotine in $\alpha 4 \mathrm{KO}$ and Leu9'Ala. Summing this activity in the Leu9'Ala mice illustrates that selective activation of $\alpha 4^{*}$ nAChRs by $0.015 \mathrm{mg} / \mathrm{kg}$ nicotine produces significant locomotor activation (Fig. 4D, Day 1: $452 \pm 79$ counts compared to Day 6: $919 \pm 68$ counts, $p<0.001, F=19.9$ ). Conversely, a single injection of $2 \mathrm{mg} / \mathrm{kg}$ nicotine significantly suppresses activity in $\alpha 4 \mathrm{KO}$ mice (Fig. $4 \mathrm{~A}, 759 \pm 80$ counts post saline compared to $336 \pm 61$ counts post $2 \mathrm{mg} / \mathrm{kg}$ nicotine, $p<0.001, F=17.76$, Fig. $4 \mathrm{C}$ ); and this activity suppression persists over the course of six daily injections (Fig. 4C). The right-hand axes of Figs. 4C and 4D present scales for the parameters $N$ and $A$ defined in Eqs. 5 and 6, respectively. We injected wild-type mice with $2 \mathrm{mg} / \mathrm{kg}$ nicotine once daily for six days. The first injection significantly suppressed locomotion (Fig. 4E). By the sixth injection, nicotine-induced locomotor activity was significantly increased compared to the first injection (Day $1=0.193 \pm 0.0318$ compared to Day $6=$ $0.539 \pm 0.132, p<0.05, F=6.53)$.

Fig. 4F presents the prediction of Eq. 7: nicotine-induced locomotion factors caused by simultaneous selective activation of $\alpha 4 \mathrm{nAChRs}$ and activation of non- $\alpha 4^{*} n A C h R s$. Eq 7 predicts that, in WT mice, daily nicotine injection will initially suppress locomotion, then increase activity with each successive injection. This prediction agrees well with the data of Fig. 4E.

\section{Discussion}

This report introduces a new method to evaluate the contribution of a single receptor pathway to an observed drug-induced behavior. The method requires the existence of two mutant strains: the KO strain allows one to evaluate the response due to the drug's effect on other receptors; and a hypersensitive strain (admittedly available in only rare instances) allows one to induce the response due to selective activation of the receptor itself. Furthermore the hypersensitive strain must have the same expression of the receptor, at the cellular and subcellular level; the Leu9'Ala strain meets these requirements(3, 16). One then asks whether the behavior of the WT strain is the sum or product 
(as appropriate) of the behavior observed in the KO strain and that observed in the hypersensitive strain. One certainly expects such an analysis to apply well at the level of electrophysiological data on single cells; but the present paper shows that the analysis yields straightforward results when applied to physiological and behavioral responses at the whole-animal level. It is important for such a straightforward analysis that all strains are on an isogenic background. To avoid confounds produced by genetic variability, and to facilitate comparison between strains, both $\alpha 4 \mathrm{KO}$ and Leu9'Ala mice in the relevant experiments were backcrossed to $\mathrm{C} 57 \mathrm{BL} / 6 \mathrm{~J}$ mice for at least eight generations.

Selective activation of $\alpha 4^{*}$ nAChRs with low doses of nicotine in Leu9'Ala mice causes hypothermia. At higher doses, nicotine also induces hypothermia in WT animals; and at still higher does, in mice that do not express $\alpha 4^{*}$ nAChRs (Figure $1 \mathrm{~A}$ ). While nicotine-induced hypothermia in both mutant strains is centrally mediated and sensitive to blockade by the noncompetitive nicotinic receptor antagonist, mecamylamine (Figure 1B, and (16)), only $\alpha 4$-mediated hypothermia is blocked by a D1 antagonist; thus the two hypothermic responses are pharmacologically distinct (Figure 1C and 1D). Based on these data, nicotine-induced hypothermia in wild-type mice is initiated by activation of at least two receptor subtypes--one containing $\alpha 4$ subunits, and the other(s) containing non- $\alpha 4$ subunits. Note that the shift between $\mathrm{KI}$ and WT is much greater than the shift between WT and KO in nicotine-induced hypothermia; for instance, $1 \mathrm{mg} / \mathrm{kg}$ induces partial hypothermia in both WT and KO mice. The latter point implies that the $\alpha 4$-dependent component is not necessary for nicotine-induced hypothermia. On the other hand, the $\alpha 4$-dependent component displays tolerance in our experiments, while the $\alpha 4$-independent component does not. Interestingly, in $\beta 2$ knockout mice nicotine-induced hypothermia responses resemble our data with $\alpha 4$ knockouts, consistent with the idea that hypothermiacontrolling $\alpha 4^{*} \mathrm{nAChRs}$, like most $\alpha 4^{*} \mathrm{nAChRs}$, also contain the $\beta 2$ subunit(11).

Previously, we found that daily selective activation of $\alpha 4^{*} \mathrm{nAChRs}$ in Leu9'Ala mice elicited tolerance to nicotine-induced hypothermia. Nicotine responses were attenuated by $>75 \%$ by the seventh daily exposure. However, when challenged with daily nicotine doses that produce hypothermia, WT animals develop tolerance to a significantly lesser extent than Leu9'Ala mice. Figure 2 illustrates that this arises from at least two different nicotinic receptor dependent mechanisms. The $\alpha 4$-mediated hypothermic component isolated in Leu9'Ala mice develops profound tolerance, whereas activation of the non- $\alpha 4^{*}$ nAChR component in $\alpha 4 \mathrm{KO}$ mice does not change with repetitive nicotine exposure. Summing these two independent responses predicts the wild-type tolerance response. Together, these data indicate that activation of $\alpha 4^{*} \mathrm{nAChRs}$ is both necessary and sufficient for tolerance development of the hypothermic response.

In rats, single daily nicotine injections produce sensitization to the locomotor actions of nicotine $(4,5)$. However, in WT mice, acute nicotine initially suppresses activity (Figures 3A, 4E). With successive daily exposures, mice develop modest tolerance to this suppression. Previous studies have shown that 
mice lacking $\beta 2^{*}$ nAChR expression are less sensitive to nicotine induced locomotor suppression at low doses of nicotine, but equally sensitive at high doses (18). Similarly, we find that $\alpha 4 \mathrm{KO}$ animals are equally sensitive to locomotor suppression compared to WT animals at high nicotine doses (i.e. 2 $\mathrm{mg} / \mathrm{kg}$ ). Interestingly, selective activation of $\alpha 4^{\star} \mathrm{nAChR}$ in Leu9'Ala mice does not acutely suppress locomotor activity at the doses we have measured.

Here we show that the biphasic WT locomotor profile likely arises from at least two combined nicotine actions with opposite effects on locomotor activity. Activation of non- $\alpha 4^{*}$ nAChRs in $\alpha 4 \mathrm{KO}$ mice suppresses locomotor activity, and this effect persists with every daily exposure (Figures $4 A$ and $4 C$ ). Selective activation of $\alpha 4^{*} \mathrm{nAChRs}$, on the other hand, produces time- and exposuredependent increases in activity (Figures $4 B$ and $4 D$ ). In wild-type mice, these two mechanisms converge: non- $\alpha 4^{*} n A C h R$ activation initially suppresses activity but, with continued daily activation of $\alpha 4^{*} n A C h R s$, activity increases, producing the observed locomotor patterns seen with repeated nicotine exposure.

Although this study does not directly explore mechanisms, the locomotor data, and their dependence on dopaminergic processes (16), are consistent with recent observations on $\alpha 4^{*}$ receptor changes during chronic nicotine at the cellular and circuit level in the midbrain (14). On day 1 , nicotine $(1.5-2 \mathrm{mg} / \mathrm{kg})$ suppresses locomotion equally in WT and $\alpha 4 \mathrm{KO}$ mice, consistent with the idea that nicotine-induced locomotor suppression at high doses involves non- $\alpha 4 \beta 2^{*}$ receptors $(10,18)$, although the responding neurons are unknown. Repeated nicotine applications would increase the number of functional $\alpha 4^{*}$ levels in some GABAergic neurons (14). In response to nicotine, such upregulated $\alpha 4^{*}$ receptors would increase firing in the GABAergic neurons, inhibiting the downstream neurons that produce locomotor suppression via non- $\alpha 4 \beta 2$ receptors; the latter receptors would not change sensitivity during repeated nicotine applications. Thus, tolerance to nicotine-induced locomotor suppression would occur in a circuit. That selective activation of $\alpha 4^{*}$ receptors produces no initial locomotor suppression, but does eventually induce locomotor activation, may indicate that there is, initially, also ongoing suppression of locomotor activity, in keeping with present concepts about the complementary roles of the direct and indirect pathways in the basal ganglia.

For our calculations, we elicited hypothermia and activity measurements with $2 \mathrm{mg} / \mathrm{kg}$ nicotine in $\alpha 4 \mathrm{KO}$ animals and $0.015 \mathrm{mg} / \mathrm{kg}$ in Leu9'Ala mice, doses that yield equivalent decreases in body temperature when acutely administered to drug-naïve animals of each strain. Previously, we have found that nicotineinduced hypothermia accurately reflects nicotine sensitivity to a number of behavioral and physiological responses. However, it could be argued that the Leu9'Ala dose is near the plateau phase of the nicotine-hypothermia dose response relation for this strain, and that tolerance development may be due to a ceiling effect. Such a ceiling mechanism is rendered unlikely by the observations that tolerance occurs at multiple hypothermia-inducing doses, including doses that do not saturate the dose-response relation (3). The combined $\alpha 4 \mathrm{KO}$ and 
Leu9'Ala responses accurately account for WT tolerance to both hypothermia and locomotor suppression elicited by $2 \mathrm{mg} / \mathrm{kg}$ nicotine, a dose chosen because it would likely activate a majority of high sensitivity $\alpha 4^{*} n A C h R s$ while also activating non- $\alpha 4^{*} n A C h R s$ to the same extent as an equal dose in $\alpha 4 \mathrm{KO}$ mice.

Together, our data indicate that $\alpha 4^{*} \mathrm{nAChR}$ activation is necessary and sufficient for the development of tolerance as measured by daily injections of nicotine.

\section{References}

1. Baker A and Meert T. Morphine and d-amphetamine nullify each others' hypothermic effects in mice. Pharmacol Toxicol 92: 64-70, 2003.

2. Chaperon F, Tricklebank MD, Unger L, and Neijt HC. Evidence for regulation of body temperature in rats by dopamine $\mathrm{D} 2$ receptor and possible influence of D1 but not D3 and D4 receptors. Neuropharmacology 44: 10471053, 2003.

3. Fonck C, Cohen BN, Nashmi R, Whiteaker P, Wagenaar D, RodriguesPinguet N, Deshpande P, Kwoh S, Munoz J, Labarca C, Collins A, Marks M, and Lester $\mathbf{H}$. Novel seizure phenotype and sleep disruptions in knock-in mice with hypersensitive $\alpha 4$ nicotinic receptors. J Neurosci 25: 11396-113411, 2005. 4. Ksir C, Hakan R, Hall DP, Jr., and Kellar KJ. Exposure to nicotine enhances the behavioral stimulant effect of nicotine and increases binding of [3H]acetylcholine to nicotinic receptors. Neuropharmacology 24: 527-531, 1985.

5. Ksir C, Hakan RL, and Kellar KJ. Chronic nicotine and locomotor activity: influences of exposure dose and test dose. Psychopharmacology (Berl) 92: 25-29, 1987.

6. Laviolette SR and van der Kooy D. The neurobiology of nicotine addiction: bridging the gap from molecules to behaviour. Nat Rev Neurosci 5: 5565, 2004.

7. Lester H, Fonck C, Tapper A, McKinney S, Damaj M, Balogh S, Owens J, Wehner J, Collins A, and Labarca C. Hypersensitive knock-in mouse strains identify receptors and pathways for nicotine action. Current Opinion in Drug Development 6: 633-639, 2003.

8. Marks MJ, Burch JB, and Collins AC. Genetics of nicotine response in four inbred strains of mice. J Pharmacol Exp Ther 226: 291-302, 1983.

9. Marubio LM, del Mar Arroyo-Jimenez M, Cordero-Erausquin M, Lena C, Le Novere N, de Kerchove d'Exaerde A, Huchet M, Damaj MI, and Changeux JP. Reduced antinociception in mice lacking neuronal nicotinic receptor subunits. Nature 398: 805-810, 1999.

10. Marubio LM, Gardier AM, Durier S, David D, Klink R, Arroyo-Jimenez MM, McIntosh JM, Rossi F, Champtiaux N, Zoli M, and Changeux JP. Effects of nicotine in the dopaminergic system of mice lacking the $\alpha 4$ subunit of neuronal nicotinic acetylcholine receptors. Eur J Neurosci 17: 1329-1337, 2003.

11. McCallum SE, Collins AC, Paylor R, and Marks MJ. Deletion of the $\beta 2$ nicotinic acetylcholine receptor subunit alters development of tolerance to 
nicotine and eliminates receptor upregulation. Psychopharmacology (Berl) 184: 314-327, 2006.

12. McGehee DS, Heath MSJ, Gelber S, Devay P, and Role LW. Nicotine enhancement of fast excitatory synaptic transmission in CNS by presynaptic receptors. Science 269: 1692-1696, 1995.

13. Miner LL, Marks MJ, and Collins AC. Classical genetic analysis of nicotine-induced seizures and nicotinic receptors. J Pharmacol Exp Ther 231: 545-554, 1984.

14. Nashmi R, Xiao C, Deshpande P, McKinney S, Grady S, Whiteaker P, Huang Q, McClure-Begley TD, Lindstrom J, Labarca C, Collins A, Marks M, and HA L. Cell specifically upregulated $\alpha 4^{*}$ nicotinic receptors: basis for both tolerance and cognitive sensitization. $J$ Neurosci in press, 2007.

15. Ross SA, Wong JY, Clifford JJ, Kinsella A, Massalas JS, Horne MK, Scheffer IE, Kola I, Waddington JL, Berkovic SF, and Drago J. Phenotypic characterization of an $\alpha 4$ neuronal nicotinic acetylcholine receptor subunit knockout mouse. J Neurosci 20: 6431-6441, 2000.

16. Tapper A, McKinney S, Nashmi R, Schwarz J, Deshpande P, Labarca C, Whiteaker $\mathbf{P}$, Collins $\mathbf{A}$, and Lester $\mathbf{H}$. Nicotine activation of $\alpha 4^{*}$ receptors: sufficient for reward, tolerance and sensitization. Science 306: 1029-1032, 2004.

17. Tapper AR, Nashmi R, and Lester H. Neuronal Nicotinic Acetylcholine Receptors and Nicotine Dependence. In: The Cell Biology of Addiction, edited by Jonathan D. Pollock BM, Christine A. Colvis, and Joni L. Rutter Cold Spring Harbor, NY 11724: Cold Spring Harbor Laboratory Press, 2005.

18. Tritto T, McCallum SE, Waddle SA, Hutton SR, Paylor R, Collins AC, and Marks MJ. Null mutant analysis of responses to nicotine: deletion of $\beta 2$ nicotinic acetylcholine receptor subunit but not $\alpha 7$ subunit reduces sensitivity to nicotine-induced locomotor depression and hypothermia. Nicotine Tob Res 6: 145-158, 2004.

19. Wooltorton JR, Pidoplichko VI, Broide RS, and Dani JA. Differential desensitization and distribution of nicotinic acetylcholine receptor subtypes in midbrain dopamine areas. J Neurosci 23: 3176-3185, 2003.

\section{Figure Legends}

Fig. 1: Expression and pharmacology of nicotine-induced hypothermia in Leu9'Ala, $\alpha 4 \mathrm{KO}$ and WT mice: A) Dose-response relation for WT (black squares), Leu9'Ala homozygous (black triangles) and $\alpha 4 \mathrm{KO}$ homozygous mice (open triangles) challenged with nicotine. Each data point represents peak temperature drops from 4-10 animals, 15-40 min after the injection; see Tapper et al., 2004. B) Temperature response in $\alpha 4 \mathrm{KO}$ mice elicited by i.p. injection of $2 \mathrm{mg} / \mathrm{kg}$ nicotine $15 \mathrm{~min}$ after either a saline (left, $\mathrm{n}=5$ )) or mecamylamine (right, $2 \mathrm{mg} / \mathrm{kg}, \mathrm{n}=6$ ) injection. C) Temperature response in Leu9'Ala $\alpha 4$ mice elicited by i.p. injection of $0.030 \mathrm{mg} / \mathrm{kg}$ nicotine $15 \mathrm{~min}$ after either a saline (left, $\mathrm{n}=6)$ ) or $\mathrm{SCH} 29930$ (right, $2 \mathrm{mg} / \mathrm{kg}, \mathrm{n}=8$ ) injection. D) Temperature response in $\alpha 4 \mathrm{KO}$ 
mice elicited by i.p. injection of $2 \mathrm{mg} / \mathrm{kg}$ nicotine $15 \mathrm{~min}$ after either a saline (left, $\mathrm{n}=6$ ) or $\mathrm{SCH} 29930$ (right, $2 \mathrm{mg} / \mathrm{kg}, \mathrm{n}=6$ ) injection. Data are expressed as mean \pm SEM. Significance was measured via one-way ANOVA (Tukey posthoc). ${ }^{\star \star} p<0.01,{ }^{\star \star \star} p<0.001$.

Fig. 2: Hypothermia tolerance profiles in Leu9'Ala, $\alpha 4 \mathrm{KO}$ and WT mice. A) Representative body temperature recordings from $\alpha 4 \mathrm{KO}$ (left) and Leu9'Ala (right) homozygous mice immediately after 1 (black trace), 4 (blue trace) or 7 (red trace) daily nicotine injections (i.p. $2 \mathrm{mg} / \mathrm{kg}$ and $0.015 \mathrm{mg} / \mathrm{kg}$, respectively). B. Nicotine-induced hypothermia tolerance profiles in Leu9'Ala homozygous and $\alpha 4$ $\mathrm{KO}$ mice challenged with one daily injection (i.p.) of $0.015 \mathrm{mg} / \mathrm{kg}$ (Leu9'Ala, $\mathrm{n}=$ 7 ) or $2 \mathrm{mg} / \mathrm{kg}(\alpha 4 \mathrm{KO}, \mathrm{n}=5-6)$ for seven days. The scale of the right hand axis represents normalization to summed values from day 1 (Eqs 1,2). C) Nicotineinduced hypothermia tolerance profile from WT mice injected with $2 \mathrm{mg} / \mathrm{kg}$ nicotine i.p. once daily for seven days $(n=5)$. The scale of the right hand axis represents the response normalized to day 1 response (Eq. 3). D) Predicted (filled triangles, Eq. 4) and actual (open triangles) tolerance profile for wild-type mice, according to Eq. 4. In all experiments, mice were injected with saline once daily for $\geq 3 \mathrm{~d}$ prior to nicotine injections. Saline injections $<2^{\circ} \mathrm{C}$ changes in body temperature. Data are expressed as mean \pm SEM. Significance was measured via one-way ANOVA (Tukey post-hoc). ${ }^{*} p<0.05,{ }^{* *} p<0.01,{ }^{* * *} p<0.001$ compared to first drug exposure.

Fig.3: Nicotine-induced locomotor activity in WT, Leu9'Ala, and $\alpha 4$ KO mice. A) Locomotor responses in WT mice after 1,3 , and 6 daily injections of $0.015,0.5$, 0.75 , or $1.5 \mathrm{mg} / \mathrm{kg}$ nicotine B) Locomotor responses in Leu9'Ala homozygous mice after 1,3 , and 6 daily injections of $0.0075,0.010,0.015$, or $0.030 \mathrm{mg} / \mathrm{kg}$ nicotine. In A) and B), each data point represents 30 min of activity immediately following drug injection. ${ }^{*} p<0.05,{ }^{* * *} p<0.001$ compared to saline (day 0 ). \# $p$ $<0.05$ compared to first drug exposure in panel $A$ and $\# p<0.05$ compared to $0.0075 \mathrm{mg} / \mathrm{kg}$ day 6 in panel B. C) Locomotor response to acute injection of saline or nicotine $(0.50,1.0$, or $2.0 \mathrm{mg} / \mathrm{kg})$ in $\alpha 4 \mathrm{KO}$ mice. Each bar represents activity summed over 30 min immediately following injection. D) Locomotor responses in $\alpha 4 \mathrm{KO}$ mice injected with $2 \mathrm{mg} / \mathrm{kg}$ nicotine $15 \mathrm{~min}$ after an injection of either saline (left bar) or $2 \mathrm{mg} / \mathrm{kg}$ mecamylamine (middle bar). Mice that received mecamylamine prior to nicotine injection were injected with nicotine alone $24 \mathrm{hr}$ later (right bar). Data are expressed as mean \pm SEM. Significance was measured via one-way ANOVA (Tukey post-hoc). Each bar represents 15 min activity immediately following nicotine injection. ${ }^{\star} p<0.05,{ }^{*} p<0.01$.

Fig. 4: Prediction of nicotine-induced locomotor activity in WT mice via nicotine responses in $\alpha 4 \mathrm{KO}$, and Leu9'Ala, homozygotes. Activity pattern immediately following saline or 1,3 , or 6 daily nicotine exposures in A) $\alpha 4 \mathrm{KO}(2 \mathrm{mg} / \mathrm{kg}$ nicotine, i.p.) or B) Leu9'Ala (0.015 mg/kg nicotine i.p.) mice. Activity counts were acquired at $30 \mathrm{sec}$ intervals. Summed locomotor activity $(L)$ was elicited by single daily i.p. injections of $2 \mathrm{mg} / \mathrm{kg}$ nicotine in C) $\alpha 4 \mathrm{KO}(\mathrm{n}=6)$ or D) 0.015 
$\mathrm{mg} / \mathrm{kg}$ injection in Leu9'Ala homozygous mice $(\mathrm{n}=8)$. See Eqs. (6) and (7) for definitions of $A$ and $N$. E) Measured locomotor response (L) to single daily injections of $2 \mathrm{mg} / \mathrm{kg}$ nicotine in WT mice $(n=11)$. F) Predicted daily locomotor responses to $2 \mathrm{mg} / \mathrm{kg}$ in $W T$ mice $\left(A(n)^{\star} N(n)\right)$, see Eq. 7). Each bar graph represents the averaged sum of $30 \mathrm{~min}$ home cage activity immediately following injection. Baseline activity after saline injection is indicated by the dotted line. Data are expressed as mean \pm SEM. All animals were injected with saline once daily for at least 3 days prior to the start of the experiment. Significance was determined by one-way ANOVA (Tukey post-hoc). ${ }^{*} p<0.05$, ${ }^{* * *} p<0.001$ compared to baseline responses after a saline injection. 
A
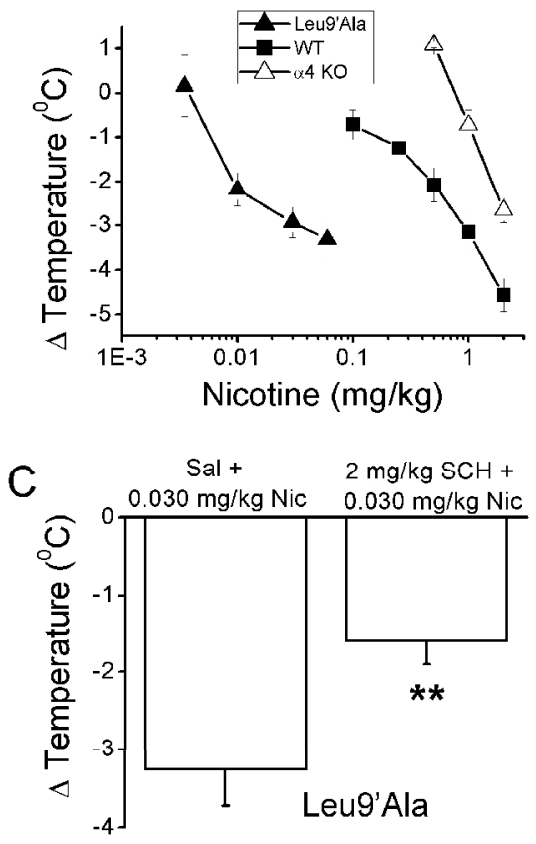

B
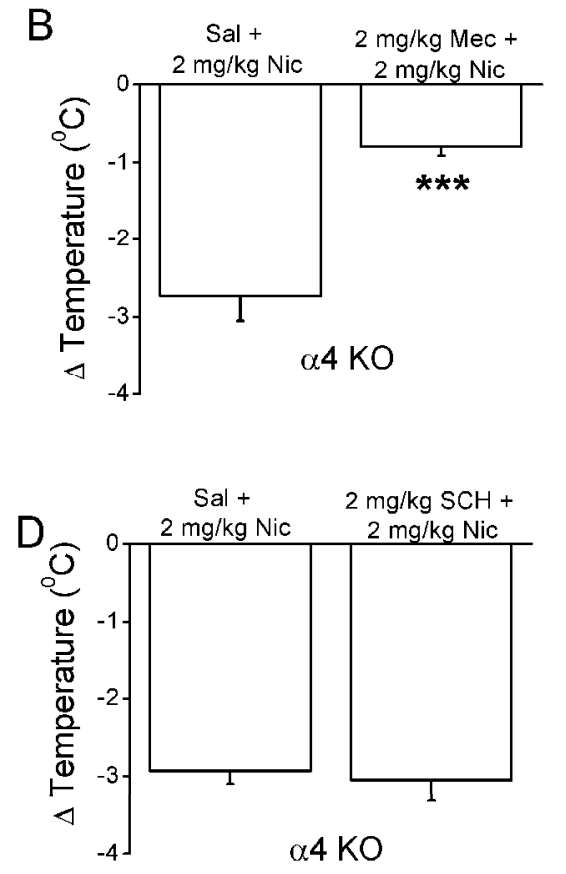

Tapper et al, Figure 1

$254 \times 190 \mathrm{~mm}(300 \times 300$ DPI $)$ 
A
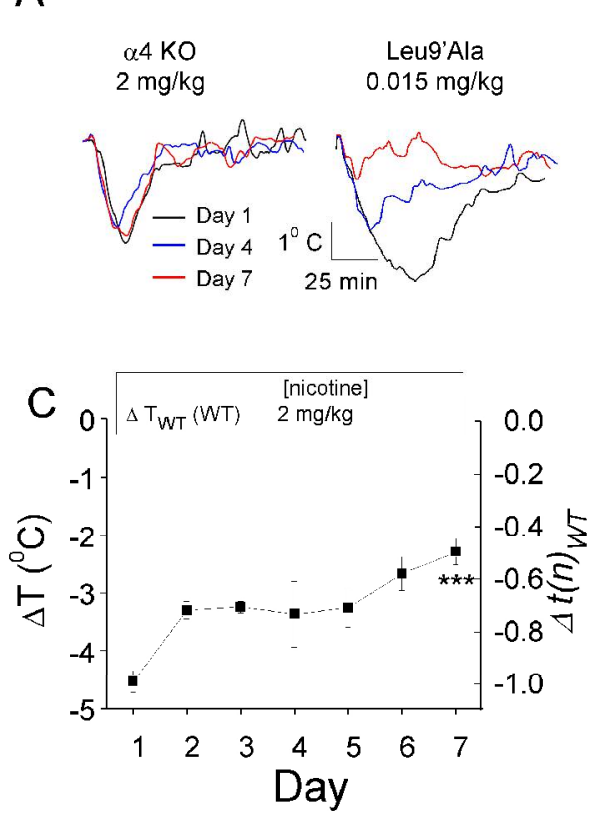
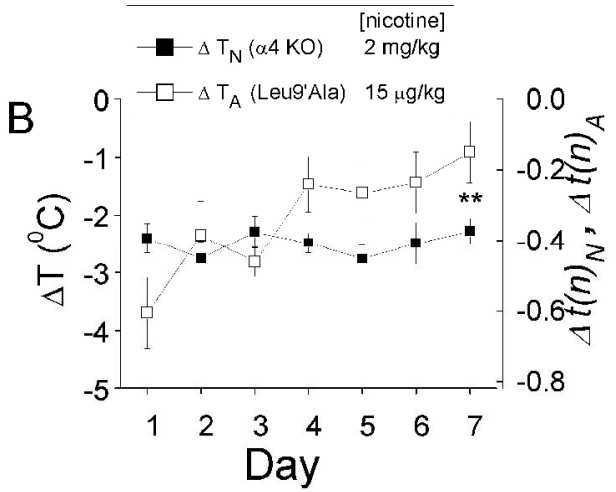

D $\quad 0.0 \quad \Delta \quad \Delta \mathrm{t}_{\mathrm{A}}+\Delta \mathrm{t}_{\mathrm{N}}$

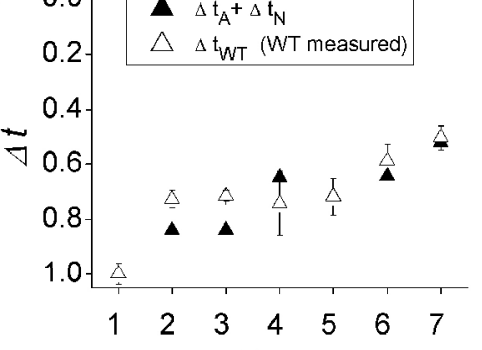

Day Tapper et al, Figure 2

$254 \times 190 \mathrm{~mm}(300 \times 300 \mathrm{DPI})$ 
A
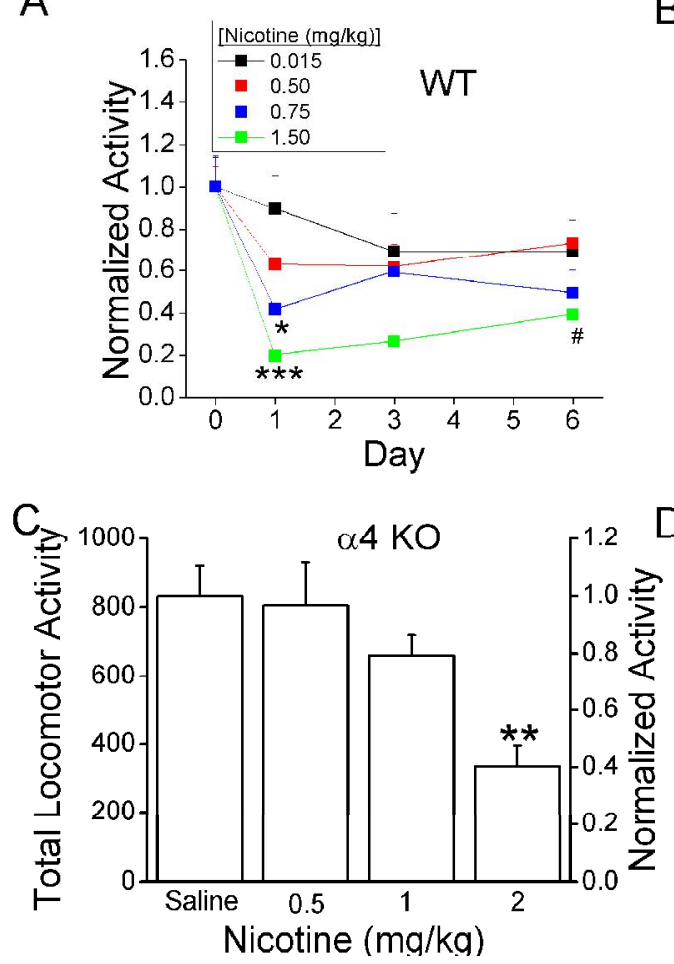

B
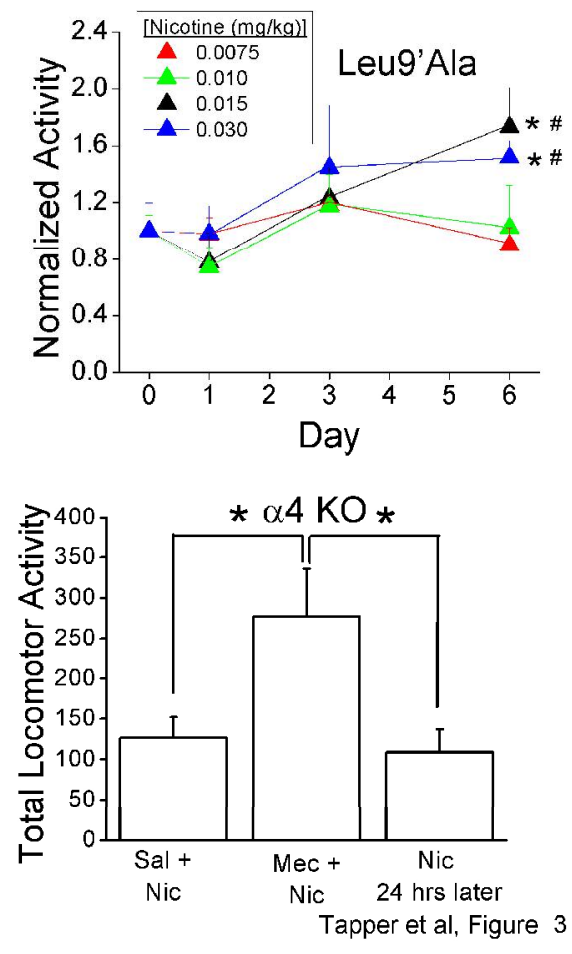

$254 \times 190 \mathrm{~mm}(300 \times 300 \mathrm{DPI})$ 


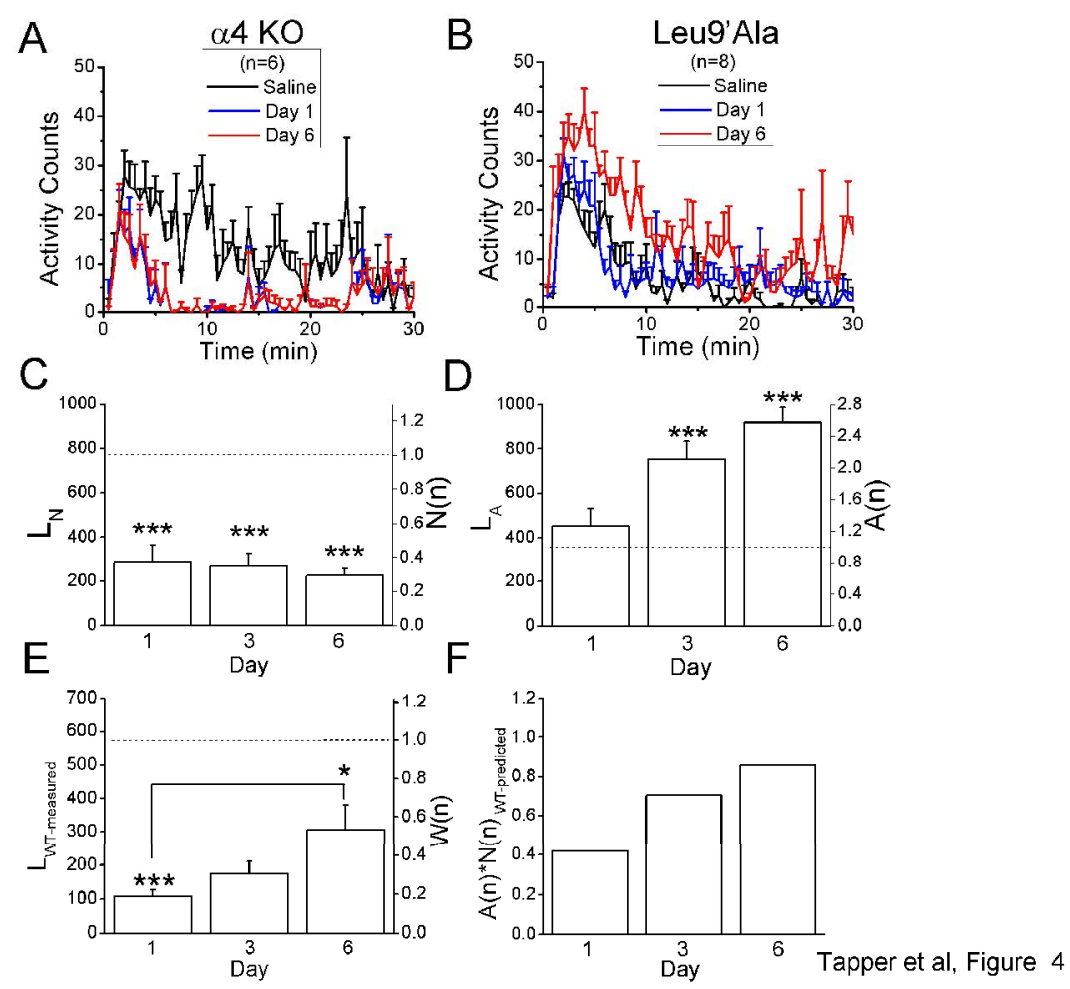

254×190mm (300 x 300 DPI) 